\title{
A rare complication: incarceration of a colonoscope in an inguinal hernia
}

We wish to report a rare complication of colonoscopy with incarceration of the colonoscope in an inguinal hernia.

An 81-year-old man underwent colonoscopy for routine surveillance. He had a rather large left inguinal hernia that was not reducible. However, he had not presented for this disease before colonoscopy. After he was consciously sedated with pethidine hydrochloride, the procedure was performed without difficulty until the cecum was reached at approximately $120 \mathrm{~cm}$. As the colonoscope was withdrawn, the colon was observed. However, at approximately $60 \mathrm{~cm}$ the colonoscope could not be withdrawn further although the lumen was clearly visible. Thus, the colonoscope appeared to be inexplicably frozen in position. On examining the left inguinal hernia, it became clear that the colonoscope had become incarcerated within the hernia sac and could not be withdrawn even with gentle external traction. The patient was taken immediately to the X-ray room, where the colonoscope together with a part of the small intestine was shown, as expected, to be within the hernia sac ( $\bullet$ Fig. 1). Under radiographic guidance, the colonoscope was slowly and carefully withdrawn by gentle traction without incident. The procedure was terminated, and the patient was referred to the surgery department for consideration for hernia repair.

There have been two reports of restoration of this complication, with radiographic guidance [1] or by external manual pressure [2]. The presence of an inguinal hernia is not a contraindication to colonoscopy. However, a careful history and physical examination before colonoscopy are important because they can put the endoscopist on the alert for a potential hazard such as the one we encountered.

Endoscopy_UCTN_Code_CPL_1AJ_2AB

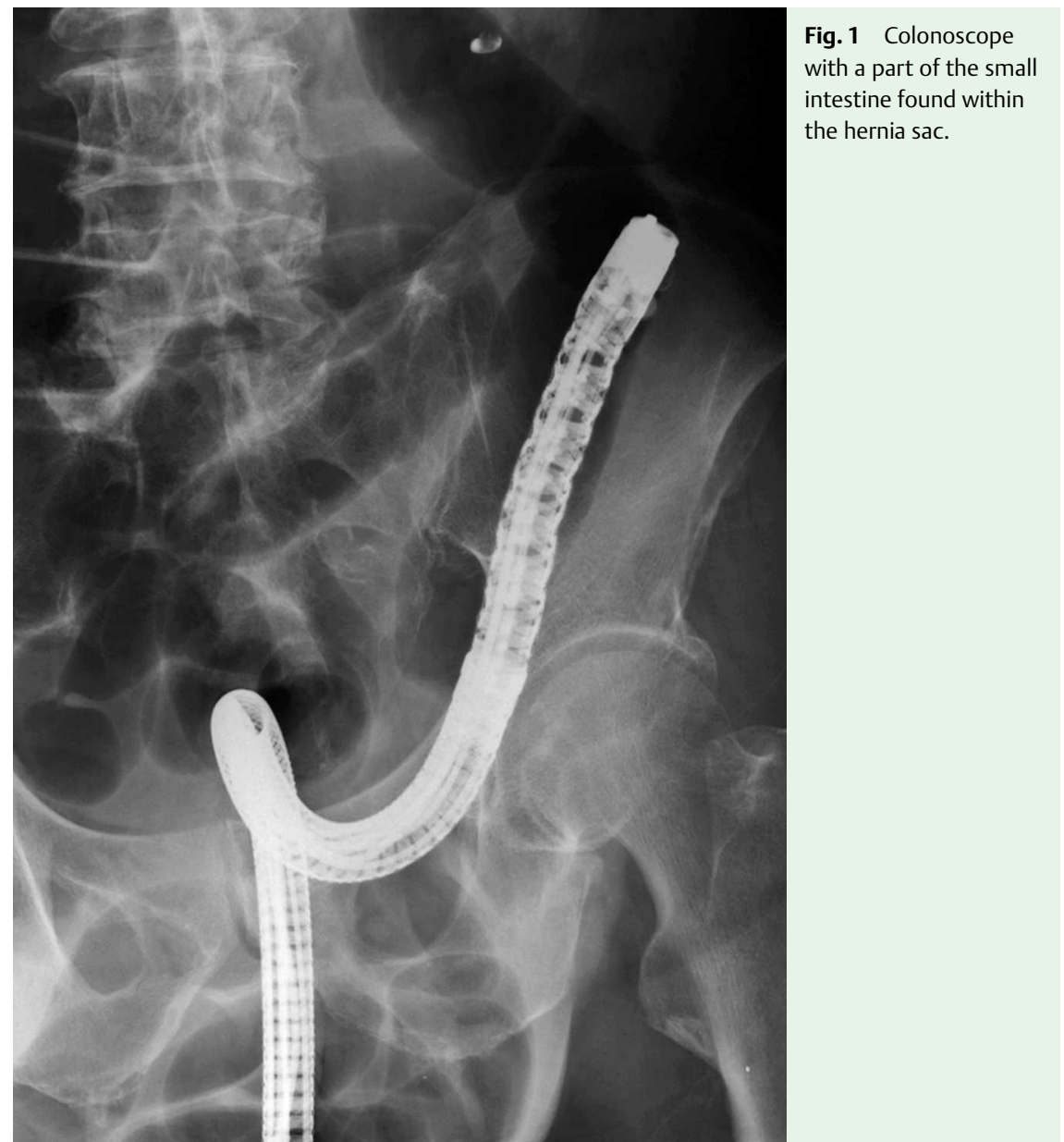

\section{K. Kume, I. Yoshikawa, M. Harada}

Third Department of Internal Medicine, University of Occupational and Environmental Health Japan, School of Medicine, Kitakyusyu, Japan

\section{References}

1 Yamamoto M, Kadakia SC. Incarceration of a colonoscope in an inguinal hernia. Gastrointest Endosc 1994; 40: 396 - 397

2 Leisser A, Delpre G, Kadish U. Colonoscope incarceration: an avoidable event. Gastrointest Endosc 1990; 36: 637-638
Bibliography

DOI $10.1055 / \mathrm{s}-0029-1214773$

Endoscopy 2009; 41: E172

(c) Georg Thieme Verlag KG Stuttgart · New York ISSN 0013-726X

\section{Corresponding author}

\section{K. Kume, MD, PhD}

Third Department of Internal Medicine University of Occupational and Environmental Health Japan

School of Medicine

1-1, Iseigaoka

Yahatanishi-ku

Kitakyusyu 807-8555

Japan

Fax: +81-93-6920107

k-kume@med.uoeh-u.ac.jp 